\title{
ANALISIS RASIO LIKUIDITAS DAN SOLVABILITAS PADA PERUSAHAAN DAERAH AIR MINUM (PDAM) TIRTA LEMATANG LAHAT
}

\author{
Oleh: Liska Novia Sari ${ }^{1}$, Yasir Arafat ${ }^{2}$, Riswan Aradea ${ }^{3}$ \\ (UNIVERSITAS PGRI PALEMBANG)
}

$\underline{\text { liskanoviasari2297@yahoo.com }}{ }^{1}, \underline{\text { riswanaradea@ gmail.com }}{ }^{3}$

\begin{abstract}
Abstrak-Tujuan penelitian ini yaitu untuk mengetahui rasio likuiditas dan solvabilitas pada Perusahaan Daerah Air Minum Tirta Lematang di Kabupaten Lahat. Objek penelitian laporan keuangan Perusahaan Daerah Air Minum Tirta Lematang Kabupaten Lahat periode 2015- 2017. Metode yang digunakan adalah deskriftip kualitatif. Hasil penelitian rasio likuiditas dilihat dari perhitungan current ratio tahun 2015 (11,62\%), tahun 2016 (317,50\%), dan tahun 2017 (0\%). Sedangkan rasio likuiditas dilihat dari perhitungan dengan quick ratio tahun 2015 (10,54\%), tahun 2016 (306,18\%), dan tahun 2017 (0\%). Berdasarkan perhitungan rasio likuiditas dan solvabilitas dapat disimpulkan bahwa PDAM Tirta Lematang berada pada kriteria tidak sehat karena sesuai dengan standar penilaian kesehatan dapat dikatakan sehat apabila $>65 \%$. Rasio solvabilitas PDAM Tirta Lematang dilihat dari perhitungan debt to assets ratio tahun 2015 (345,54\%), tahun 2016 (17,00\%) dan tahun 2017 (47,86\%). Rasio solvabilitas dilihat dari perhitungan debt to equity ratio tahun 2015 (140,73\%), tahun 2016 (20,96\%) dan tahun 2017 (91,80\%). Berdasarkan perhitungan rasio likuiditas dan solvabilitas dapat disimpulkan bahwa PDAM Tirta Lematang berada pada kriteria tidak sehat karena sesuai dengan standar penilaian kesehatan dapat dikatakan sehat apabila $>65 \%$.
\end{abstract}

Kata Kunci : Analisis Rasio Likuiditas dan Solvabilitas, Perusahaan Daerah Air Minum

\begin{abstract}
The purpose of this study was to determine the ratio of liquidity and solvency in the Tirta Lematang Regional Water Company in Lahat Regency. The object of the study of Tirta Lematang Regional Water Supply Company is Lahat Regency 2015-2017 period. The method used is qualitative descriptive. The results of the liquidity ratio research of PDAM Tirta Lematang can be seen from the calculation of current ratio in 2015 (11.62\%), 2016 (317.50\%), and 2017 $(0 \%)$. While the liquidity ratio is seen from the calculation with a quick ratio in 2015 (10.54\%), 2016 (306.18\%), and 2017 (0\%). Based on the calculation of the liquidity and solvency ratios, it can be concluded that PDAM Tirta Lematang is in an unhealthy criteria because it is in accordance with the health assessment
\end{abstract}


standards can be said to be healthy if $>65 \%$. The solvency ratio of PDAM Tirta Lematang can be seen from the calculation of the debt to assets ratio in 2015 (345.54\%), 2016 (17.00\%) and 2017 (47.86\%). The solvency ratio can be seen from the calculation of debt to equity ratio in 2015 (140.73\%), 2016 (20.96\%) and 2017 (91.80\%). Based on the calculation of the liquidity and solvency ratios, it can be concluded that PDAM Tirta Lematang is in an unealthy criteria because it is in accordance with the health assessment standards can be said to be healthy if $>65 \%$.

Keywords : Analysis of Liquidity and Solvency Ratios, Regional Water Companies

\section{PENDAHULUAN}

Ketergantungan manusia terhadap air semakin besar sejalan dengan bertambahnya penduduk karena air adalah sumber kebutuhan pokok bagi manusia salah satunya seperti minum. Menurut UndangUndang Republik Indonesia Nomor 7 Tahun 2004 tentang Sumber Daya Air Presiden Republik Indonesia Pasal 3 bahwa sumber daya air dikelola secara meyeluruh, terpadu, dan berwawasan lingkungan hidup dengan tujuan mewujudkan kemanfaatan sumber daya air yang berkelanjutan untuk sebesar- besar kemakmuran rakyat. Sedangkan Menurut Undang- Undang Republik Indonesia Nomor 32 Tahun 2004 Tentang Pemerintah Daerah Presiden Republik Indonesia Pasal 1 bahwa Pemerintah Daerah adalah penyelenggara urusan pemerintah daerah dan DPRD menurut asas otonomi dan tugas pembantuan dengan prinsip otonomi seluasluasnya dalam sistem dan prinsip Negara Kesatuan Republik Indonesia sebagaimana dimaksudkan dalam
Undang- Undang Dasar Negara Republik Indonesia Tahun 1945. Pengelola sumber daya air merupakan tanggung jawab Pemerintah Daerah/ Kabupaten untuk mewujudkan kemanfaatan sumber daya air dan kemakmuran rakyat yang pelaksanaannya dilakukan oleh Perusahaan Daerah Air Minum (PDAM).

Perusahaan Daerah Air Minum (PDAM) adalah badan usaha milik daerah yang memberikan pelayanan berupa jasa dan menyelenggarakan kemanfaatan di bidang air minum. Aktivitas PDAM antara lain mengumpulkan, mengolah, dan menjernihkan hingga mendistribusikan air kepada masyarakat/ pelanggan. Laporan yang dibuat oleh perusahaan daerah air minum umumnya adalah laporan laba rugi, laporan perubahan modal, laporan arus kas, neraca.

Kasmir

menjelaskan bahwa rasio keuangan merupakan kegiatan membandingkan angka- angka yang ada dalam laporan keuangan dengan cara 
membagi satu angka dengan angka lainnya. Perbandingan dapat dilakukan antara satu komponen dengan komponen dalam satu laporan keuangan atau antar komponen yang ada diantara laporan keuangan. Kemudian angka yang diperbandingkan dapat berupa angka- angka dalam satu periode maupun beberapa periode.Dalam penelitian ini digunakan analisis rasio likuiditas dan solvabilitas.

Menurut Harahap (2016: 301) rasio likuiditas menggambarkan kemampuan perusahaan menyelesaikan kewajiban jangka pendeknya. Dan rasio solvabilitas (leverage) adalah mengukur seberapa besar perusahaan dibiayai dengan utang. Fahmi (2011: 127)

Menurut hasil observasi awal di PDAM Kabupaten Lahat perusahaan ini membuat laporan pertanggungjawaban berupa laporan keuangan seperti laporan laba rugi, laporan perubahan modal, dan neraca tetapi belum dilakukan perhitungan rasio keuangan seperti rasio likuiditas dan rasio solvabilitas. Berdasarkan latar belakang masalah tersebut, penulis tertarik untuk membahas masalah tersebut dan menyusunnya dalam bentuk skripsi yang berjudul "Analisis Rasio Likuiditas Dan Solvabilitas Pada Perusahaan Daerah Air Minum (Pdam) Tirta Lematang Lahat".

\section{METODOLOGI PENELITIAN}

Tempat penelitian ini adalah Perusahaan Daerah Air Minum (PDAM) di Kabupaten Lahat.

Untuk mencari data dan keterangan yang diperlukan digunakan teknik sebagai berikut:

1. Observasi

Basir, dan Amrina (2017:121) observasi adalah pengamatan atau penginderaan secara khusus dengan penuh perhatian dan keuletan, sehingga objek yang tanpa observasi tidak bisa terungkap datanya menjadi terungkap datanya. Observasi dalam penelitian pendidikan dapat dilakukan secara langsung, tidak langsung atau partisipasi. Observasi langsung dilakukan tanpa perantara terhadap perilaku subjek penelitian. Observasi dilakukan di Perusahaan Daerah Air Minum Kabupaten Lahat.

2. Dokumentasi

Menurut Sugiono (2015:329) "dokumen catatan peristiwa yang sudah berlaku. Dokumen bisa berbentuk tulisan, gambar, atau karya- karya monumental dari seseorang. Menurut Arikunto (2013:274) "dokumentasi adalah mencari data, mengenai hal-hal atau variabel berupa catatan, transkip, buku, surat kabar, majalah, prasasti, notulen rapat, legger agenda, dan sebagainya". Teknik ini digunakan untuk mengetahaui laporan keuangan dan buku-buku yang digunakan. Data ini merupakan data sekunder. 
3. Wawancara

Menurut Basir, dan Amrina (2017:117) wawancara merupakan suatu teknik pengumpulan data yang utama. Wawancara mendalam dilakukan untuk mengetahui bukan aspek- aspek yang dapat dikenali, melainkan hal- hal yang ada balik munculnya fenomena. Menurut Sugiono (2015:317) wawancara digunakan sebagai teknik pengumpulan data apabila peneliti ingin melakukan studi pendahuluan untuk menemukan permasalahan yang harus diteliti, tetapi juga apabila peneliti ingin mengetahui hal- hal dari responden yang mendalam. Teknik pengumpulan data ini mendasarkan diri pada laporan tentang diri sendiri atau selfreport, atau setidak-tidaknya pada pengetahuan dan keyakinan pribadi. Teknik ini digunakan untuk mengetahui informasi mengenai PDAM Tirta Lematang di Kabupaten Lahat. Wawancara ini ditunjukkan kepada karyawan PDAM Tirta Lematang di Kabupaten Lahat.

HASIL DAN PEMBAHASAN

Hasil Penelitian

Deskripsi pelaksanaan penelitian

Penelitian ini dilakukan di Perusahaan Daerah Air Minum (PDAM) di Kabupaten Lahat. Waktu penelitian ini berlangsung selama 1 Minggu, yaitu dari tanggal 10 april s.d 17 April 2019. Lokasi penelitian di Jl. Bhayangkara Bandar Jaya, Kabupaten Lahat, Sumatera Selatan. Berikut perhitungan rasio likuiditas dan solvabilitas PDAM Tirta Lematang.

Tabel 1. Perhitungan Rasio Likuiditas dan Solvabilitas PDAM Tirta Lematang

\begin{tabular}{|l|c|cc|}
\hline No. & $\begin{array}{c}\text { Aspek yang } \\
\text { Dinilai }\end{array}$ & \multicolumn{2}{c|}{ Komponen } \\
\hline 1. & Likuiditas & & \\
& & $\begin{array}{r}\text { Current Ratio } \\
\text { Current Ratio }=\frac{\text { Aktiva Lancar }}{\text { Utang Lancar }}\end{array}$ \\
& & $=\frac{662.668 .642}{5.701 .156 .179}=0,1162340798$ \\
& & $\begin{array}{r}\text { Quick Ratio } \\
\text { Quick Ratio }\end{array}$ & $=\frac{\text { Aktiva Lancar }- \text { Persediaan }}{\text { Utang Lancar }}$ \\
& & & $=\frac{662.668 .642-61.945 .300}{5.701 .156 .179}$ \\
& & & $=\frac{600.723 .342}{5.701 .156 .179}=0,1053686872$ \\
\hline
\end{tabular}




\begin{tabular}{|c|c|c|}
\hline & & 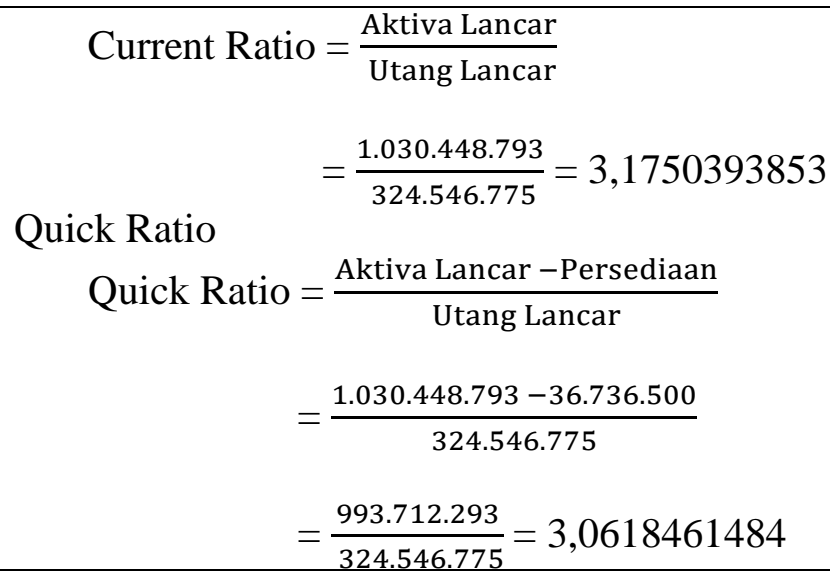 \\
\hline & 2017 & $\begin{array}{l}\text { Current Ratio } \\
\qquad \begin{aligned} & \text { Current Ratio }=\frac{\text { Aktiva Lancar }}{\text { Utang Lancar }} \\
&=\frac{2.663 .354 .841}{0}=0 \\
& \text { Quick Ratio } \\
& \text { Quick Ratio }=\frac{\text { Aktiva Lancar }- \text { Persediaan }}{\text { Utang Lancar }} \\
&=\frac{2.663 .354 .841-21.751 .000}{0}=0\end{aligned}\end{array}$ \\
\hline 2. & & Solvabilitas \\
\hline & 2015 & $\begin{array}{l}\text { Debt to Assets Ratio (Debt Ratio) } \\
\begin{aligned} & \text { Debt to assets ratio }=\frac{\text { Total Utang }}{\text { Total Aktiva }} \\
&=\frac{5.701156 .179}{1.649 .924 .875} \\
&=3,4554035324 \\
& \text { Debt to Equity Ratio } \\
& \text { Debt to Equity Ratio }=\frac{\text { Total Utang }}{\text { Total Modal }} \\
&=\frac{5.701156 .179}{4.051 .231 .322} \\
&=1,4072650327\end{aligned}\end{array}$ \\
\hline & 2016 & $\begin{array}{l}\text { Debt to Assets Ratio (Debt Ratio) } \\
\begin{aligned} & \text { Debt to assets ratio }=\frac{\text { Total Utang }}{\text { Total Aktiva }} \\
&=\frac{324.546 .775}{1.908 .945 .366} \\
&$\[ \]$=0,170013653 \\
& \text { Debt to Equity Ratio } \\
& \text { Debt to Equity Ratio }=\frac{\text { Total Utang }}{\text { Total Modal }}\end{aligned}\end{array}$ \\
\hline
\end{tabular}




\begin{tabular}{|c|c|}
\hline & $\begin{array}{l}=\frac{324.546 .775}{1.584 .398 .591} \\
=0,2096015696\end{array}$ \\
\hline 2017 & $\begin{array}{l}\text { Debt to Assets Ratio (Debt Ratio) } \\
\begin{aligned} & \text { Debt to assets ratio }=\frac{\text { Total Utang }}{\text { Total Aktiva }} \\
&=\frac{1.661 .771 .226}{3.471 .902 .804} \\
&=0,4786341438 \\
& \text { Debt to Equity Ratio } \\
& \text { Debt to Equity Ratio }=\frac{\text { Total Utang }}{\text { Total Modal }} \\
&=\frac{1.661 .771 .226}{1.810 .131 .578} \\
&=0,9180389129\end{aligned}\end{array}$ \\
\hline
\end{tabular}

Sumber: Diolah dari hasil penelitian.

\section{Pembahasan}

Berdasarkan perhitungan rasio likuiditas dan solvabilitas pada tabel 1 diatas, maka dapat diketahui bahwa rasio likuiditas tahun 2015untuk perhitungan current ratiosebesar $11,62 \%$ sedangkan perhitungan quick ratio $10,54 \%$ jika dibandingkan dengan tahun 2016 perhitungan current ratio sebesar $317,50 \%$ dan perhitungan quick ratio sebesar 306,18\% menyatakan bahwa perhitungan mengalami peningkatan current ratio sebesar 305,88\% dan quick ratio $295,64 \%$ maka peningkatan ini menunjukkan bahwa Perusahaan Daerah Air Minum Tirta Lematang Kabupaten Lahat memiliki kemampuan untuk membayar utang lancar baik. Jika dibandingkan dengan tahun 2017 perhitungan current ratio sebesar $0 \%$ dan quick ratio sebesar $0 \%$ hal ini terjadi bukan karena Perusahaan daerah air minum Tirta Lematang di kabupaten Lahat tidak mampu membayar utang lancar tetapi pada tahun 2017 perusahaan daerah air minum Tirta Lematang tidak memiliki utang lancar.Karena menurut Harahap (2016:301) rasio ini menunjukkan sejauh mana aktiva lancar menutupi kewajibankewajiban lancar. Semakin besar perbandingan aktiva lancar dengan hutang lancar maka semakin tinggi kemampuan perusahaan menutupi kewajiban jangka pendeknya. Artinya pada tahun 2017 perusahaan daerah air minum Tirta Lematang dapat dikatakan sehat. Dilihat dari standar penilaian tingkat kesehatan BUMN Tabel 3 pada Bab 2 menunjukkan bahwa perusahaan daerah air minum Tirta Lematang di kabupaten lahat dapat dikatakan tidak sehat karena persentase 
menunjukkan current ratio $11,64 \%$ dan quick ratio $10,54 \%$ sedangkan untuk penilaian yang dapat dikatakan sehat yaitu 65-95\%. Tetapi tahun 2016 dapat dikatakan sehat dengan persentase perhitungan current ratio $317,50 \%$ dan quick ratio $306,18 \%$ sudah sesuai dengan standar pengukuran. Pada tahun 2017 perusahaan daerah air minum Tirta Lematang tidak memiliki utang lancar sehingga membuat persentase 0\%. Hal ini berarti pada tahun 2017 perusahaan daerah air minum Tirta Lematang dapat dikatakan sehat. Hal ini dikarenakan rasio ini menunjukkan kemampuan aktiva lancar yang paling likuid mampu menutupi utang lancar. Semakin besar rasio ini semakin baik Harahap (2016:302).

Perhitungan rasio solvabilitas tahun 2015untuk perhitungan debt to asset ratio sebesar $345,54 \%$ sedangkan perhitungan debt to equity ratio $140,73 \%$ jika dibandingkan dengan tahun 2016 perhitungandebt to asset ratio sebesar $17,00 \%$ dan perhitungan debt to equity ratio sebesar 20,96\% menyatakan bahwa perhitungan mengalami penurunan debt to asset ratio sebesar $328,54 \%$ dandebt to equity ratio sebesar119,77\% maka penurunan ini menunjukkan bahwa Perusahaan Daerah Air Minum Tirta Lematang Kabupaten Lahat memiliki penurunan aktiva dan modal pada tahun 2016. Jika dibandingkan dengan tahun 2017 perhitungan debt to asset ratio sebesar $47,86 \%$ dan debt to equity ratio sebesar $91,80 \%$ terjadi peningkatan debt to asset ratio sebesar $30,86 \%$ dan debt to equity ratio sebesar $70,84 \%$.Dilihat dari perhitungan perusahaan daerah air minum di kabupaten lahat dapat dikatakanberada pada kriteria sehat di tahun 2015 untuk perhitungan debt to asset ratio sebesar $345,54 \%$ dan debt to equity ratio sebesar $140,72 \%$. Persentase tidak sehat pada tahun 2016 karena persentase menunjukkan untuk perhitungan debt to asset ratio sebesar $17,00 \%$ dan debt to equity ratio sebesar 20,96\%. Pada tahun 2017 berada pada 2 kriteria untuk perhitungan debt to asset ratio sebesar $47,86 \%$ artinya sesuai dengan standar pengukuran kurang sehat dan debt to equity ratio sebesar $91,80 \%$ berada pada kriteria sehat.

Hasil penelitian ini berbeda dengan penelitian sebelumnya yang dilakukan oleh (Putri: 2017) bahwa hasil penelitiannya Perusahaan Daerah Air Minum di Kabupaten Surakarta dilihat dari rasio likuiditas dan profitabilitas masuk dalam kategori perusahaan yang baik. Sedangkan berdasarkan perhitungan PDAM Tirta Lematang dilihat dari rasio likuiditas tahun 2015 (11,62\%), tahun 2016 (317,50\%), dan tahun 2017 (0\%). Sedangkan rasio solvabilitas tahun 2015 (345,54\%), tahun $2016(17,00 \%)$ dan tahun 2017 $(47,86 \%)$. Hal ini berarti kinerja keuangan PDAM Tirta Lematang berada pada kriteria tidak sehat dan 
masih perlu ditingkatkan lagi agar perusahaan tidak mengalami kerugian melalui proses evaluasi yang dilakukan secara terus menerus.

\section{KESIMPULAN DAN SARAN}

\section{Kesimpulan}

Berdasarkan hasil penelitian melalui analisis data dan pembahasan, dapat disimpulkan bahwa:

1. Rasio likuiditas PDAM Tirta Lematang dilihat dari perhitungan current ratio tahun 2015 (11,62\%), tahun $2016(317,50 \%)$, dan tahun $2017 \quad$ (0\%). Sedangkan rasio likuiditas dilihat dari perhitungan dengan quick ratio tahun 2015 (10,54\%), tahun 2016 (306,18\%), dan tahun 2017 (0\%).

Berdasarkan perhitungan rasio likuiditas dan solvabilitas dapat disimpulkan bahwa PDAM Tirta Lematang berada pada kriteria tidak sehat.

2. Rasio solvabilitas PDAM Tirta Lematang dilihat dari perhitungan debt to assets ratio tahun 2015 (345,54\%), tahun 2016 $(17,00 \%)$ dan tahun 2017 $(47,86 \%)$. Rasio solvabilitas dilihat dari perhitungan debt to equity ratio tahun 2015 (140,73\%), tahun 2016 (20,96\%) dan tahun 2017
$(91,80 \%)$. Berdasarkan perhitungan rasio likuiditas dan solvabilitas dapat disimpulkan bahwa PDAM Tirta Lematang berada pada kriteria tidak sehat.

\section{Saran}

Berdasarkan simpulan diatas, maka peneliti dapat memberikan saran sebagai berikut:

1. Sebaiknya PDAM Tirta Lematang terus melakukan proses evaluasi terhadap kinerja keuangan perusahaan agar PDAM Tirta Lematang tidak mengalami kerugian.

2. Bagi peneliti lainnya, diharapkan hasil penelitian ini dapat dijadikan atau bahan referensi sehingga dapat melakukan penelitian yang lebih luas lagi terkait dengan analisis keuangan pada perusahaan.

\section{DAFTAR PUSTAKA}

Amrina, Dian Eka., dan Basir, Djahir. 2017. Pengantar Metode Penelitian Pendidikan. Palembang: Universitas Sriwijaya.

Arikunto, Suharsimi. 2013. Prosedur Penelitian. Jakarta: PT.Rineka Cipta.

Fahmi, Irham. 2011, Analisis Laporan Keuangan. Bandung: Alfabeta.

Gunawan, Imam. 2016. Metodologi Penelitian Kualitatif. Jakarta : Bumi Aksara 
Harahap, Sofyan Syafari, 2016, Analisis Kritis atas Laporan Keuangan. Jakarta: PT RajaGrafindo Persada.

Kasmir. 2012. Analisis Keuangan edisi 5. Jakarta: PT.Raja Grafindo Persada.

Mahmud, 2011. Metode Penelitian Pendidikan. Bandung: Pustaka Setia

Munawir, 2014. Analisa Laporan Keuangan. Yogyakarta: Liberty Yogyakarta

Putri, Agustina Mahardika. 2017. Analisis Kinerja Keuangan Perusahaan Daerah Air Minum Kabupaten Surakarta. Masalah dalam penelitian ini bagaimanakah analisis Kinerja Keuangan Perusahaan Daerah Air Minum Kabupaten Surakarta. Universitas Muhammadiyah Surakarta.

Samryn, L.M. 2014. Pengantar Akuntansi. Jakarta: PT RajaGrafindo Persada.

Sugiyono. 2015. Metode Penelitian Pendidikan. Bandung: Alfabeta Sugiyono. 2017. Metode Penelitian Kuantitatif, Kualitatif, dan $R \& D$. Bandung: Alfabeta. 